\title{
ESPORTE NA PRIMEIRA REPÚBLICA: A HISTÓRIA DO ESPETÁCULO
}

\section{Bruno Jeuken*}

Universidade de São Paulo

São Paulo - São Paulo - Brasil

Resenha de: GAMBETA, Wilson. A bola rolou: o velódromo paulista e os espetáculos de futebol. São Paulo: SESI-Editora, 2015.

Os estudos acadêmicos sobre o esporte no Brasil tardaram a começar, mas desde as duas últimas décadas já não é mais possível acompanhar a quantidade de trabalhos. Por vários motivos, como aconteceu também com outros temas, os recortes temporais se concentram na Era Vargas ou em períodos imediatamente posteriores. A Bola Rolou é uma importante contribuição a uma tendência recente de estudo do início da República brasileira, um trabalho que dá sua contribuição junto a outros bons artigos, revistas e livros que versam sobre o período, além, é claro, de se tratar de uma referência nos estudos sobre esporte.

\footnotetext{
* Bacharel em História pelo Departamento de História da Faculdade de Filosofia, Letras e Ciências Humanas da Universidade de São Paulo. Mestrando em História Social pela mesma instituição. Pesquisador do NAP-LUDENS - FFLCH/USP. E-mail: brunojeukensouza@gmail.com
} 
Seja falando do Brasil ou da Europa, de educação ou de urbanismo, das alianças da elite ou da classe trabalhadora, da população negra ou dos imigrantes, do turfe, do ciclismo ou do futebol, o texto segue um fio condutor bem determinado e explicita de forma completa o processo histórico formador dos espetáculos esportivos na cidade de São Paulo, cujo palco principal foi, durante o recorte do livro, o Velódromo da Consolação. Tentarei dissecar o trabalho para expor as razões que fazem deste livro uma leitura obrigatória.

O primeiro e principal mérito do autor é explicar o futebol sem essencializá-lo. Não há nenhum argumento tautológico, autorreferente, que explique o futebol por meio dele mesmo. O que o historiador faz é descrever um processo de décadas, herdeiro de outros esportes de espetáculo. Gambeta passa ileso por inúmeras armadilhas e não comete o pecado do anacronismo. É comum encontrar análises (dentro e fora da academia) que encaram o gosto pelo futebol de forma anacrônica, como se o esporte tivesse criado, ele mesmo, suas sociabilidades e identidades, como se o espetáculo futebolístico e seu entorno tivessem nascido prontos. O objeto central do livro - $O$ Velódromo Paulista e os espetáculos de futebol - aparece aqui como resultado de um processo relativamente longo e cuidadosamente descrito. Gambeta mostra que não há nada instrínseco ao esporte que o tenha feito ser o fenômeno social amplo e poderoso que é hoje; ao contrário, o autor nos apresenta as condições, as relações de causa e consequência, as permanências e rupturas, que fizeram do futebol o fenômeno social que é.

Para tanto, alguns conceitos utilizados pelo autor merecem destaque por sua importância: o espetáculo, a parentela, e o binômio futebol informal/futebol de espetáculos.

O espetáculo, conforme Debord ${ }^{1}$, é um conjunto de relações sociais mediadas pelas imagens. O poder do espetáculo está pulverizado pela vida social, com imagens produzidas para justificar, reafirmar, reforçar o poder da classe dirigente. No caso da capital paulista, como descrito por Gambeta, o espetáculo serve como mediação entre as famílias da elite paulistana e as classes subalternas, logo ampliadas pela chegada de imigrantes. Essa elite paulistana é descrita com o conceito de parentela, como definido pela professora Maria Isaura Pereira de Queiroz, qual seja: grupos de famílias ligadas entre si, através das gerações, por relações de sangue, tradição, compadrio, religiosidade, honrarias, negociações políticas e negócios em comum. De for-

1 DEBORD, Guy. The Society of the Spectacle. New York: Zone Books, 1995. 
ma certeira, esse conceito nos ajuda a pensar o grupo social que protagoniza a formação dos espetáculos: as famílias da elite paulistana.

Destaco também o binômio futebol informal/futebol de espetáculos. A divisão consagrada pelos jornalistas Thomaz Mazzoni e Mário Filho, futebol de várzea/ futebol oficial, é muito utilizada dentro e fora da academia, apesar de ignorar uma variedade enorme de práticas e reforçar oposições que, por serem forçadas, distorcem as análises (casa e rua, pobre e rico, negro e branco). A divisão proposta por Wilson Gambeta é de extrema importância neste campo de estudo porque leva em conta a constituição da prática esportiva, não os agentes, o local ou alguma credencial. Os conceitos utilizados pelo autor operam uma diferenciação entre a prática esportiva como jogo atlético, forma de lazer, ocupação do chamado tempo livre, e a prática esportiva como espetáculo, organizada em campeonatos que reúnem os times de várias agremiações, exposta como espetáculo para grupos com os quais cria relações de identidade. Não há nesses conceitos nenhum reforço a qualquer oposição engessada Por tratar-se da constituição das práticas esportivas, o conceito consegue ao mesmo tempo ser mais preciso e mais maleável, por contraditório que pareça.

É oportuno propor uma divisão de três momentos concatenados neste livro: o início dos espetáculos esportivos no final do século XIX; os espetáculos de futebol na primeira década do século XX; e o momento de crise e ruptura no futebol de espetáculos, no qual a elite gradualmente sai de cena para praticar outros esportes enquanto o futebol (de espetáculos) começa um longo caminho até a profissionalização.

O início do livro, aparentemente desconectado dos esportes, nos mostra a relação da elite paulistana com a Europa, lugar onde esses agentes tinham contato com uma vida em transformação, no processo que foi chamado de modernização: o crescimento das cidades, o mundo industrial, os espetáculos... Uma vez de volta, essas famílias paulistanas se reuniam para emular aquilo que entendiam como uma referência ideal de vida urbana. Desse processo vem o turfe, o ciclismo e o futebol.

No início, era o turfe. Segundo o autor, havia corridas em São Paulo desde 1860, mas foi apenas em 1875 que Antonio Prado, Martinico Prado, Eleuterio Silva Prado, Elias Pacheco Chaves e Elias Fausto Pacheco Jordão uniram-se a Paes de Barros para fundar o Club Paulistano de Corridas. Pelos sobrenomes dos agentes fica clara a ação direta das parentelas na constituição dos espetáculos esportivos. Um tipo de empreendimento em grupo já antigo - se lembrarmos dos negócios dessas famílias - e que ainda se repetiria por décadas - se pensarmos no Velódromo e nas Ligas de futebol. 
A organização desse clube marca, como explica o autor, a transição entre disputas esporádicas e um esporte moderno integrado ao lazer urbano. $\mathrm{O}$ importante aqui é notar que nas corridas de cavalo, além do prazer individual, os criadores ofereciam diversão para espectadores pagantes. Como um bom trabalho de história, o texto extrapola o esporte e evidencia um retrato do último quarto do século XIX em São Paulo, o que nos faz refletir mesmo a respeito do tempo presente, como quando diz que as desigualdades eram reproduzidas entre assistentes (populares das arquibancadas e gerais) e os sportsmen e seus familiares (das tribunas reservadas), um espaço social controlado (p. 47).

O turfe paulistano, bastante instável, viveu momentos de apogeu e crise de acordo com o desempenho econômico da exportação de café. Segundo Wilson Gambeta, em determinado momento, além das crises recorrentes, as corridas se misturaram a jogos populares e ao dinheiro das apostas, cuja emoção se sobrepôs à excitação com os galopes e "empanou os espetáculos" que, antes, eram preparados para o brilho dos sportsmen da elite paulistana. (p. 63)

O historiador narra um processo histórico contínuo e explica os momentos de apogeu e crise dos esportes. Com a queda de popularidade do turfe, o ciclismo ganha espaço mas, no limite, eles são parte do mesmo processo. Temos então que a decadência do turfe foi simultânea à difusão de um outro modismo, dessa vez entre os rapazes da geração mais nova: o ciclismo.

Acerca deste momento, o autor extrapola o esporte e trata da "redefinição dos usos considerados aceitáveis para as ruas" (p. 85). Contemporâneo ao desenvolvimento do ciclismo, desenvolve-se uma forma moderna de se relacionar, criam-se espaços de convivência externa, as camadas subalternas começam a circular entre os membros das parentelas em determinados espaços - claro, desde que seguissem um certo padrão de comportamento, de trajes, conseguissem pagar o valor dos ingressos e ocupassem seus lugares bem determinados. Esse elemento não é trivial. O historiador mostra com clareza que essa convivência entre classes não foi inventada pelos espetáculos de futebol, como alguns podem concluir apressadamente, mas é algo anterior e que aparece como uma das causas, não como consequência, da sociabilidade nos estádios. O afrouxamento dos laços de sangue e a adaptação a novas formas de sociabilidade são um fenômeno observado pelo autor que é externo aos esportes mas a eles se relaciona diretamente.

Partícipe de uma nova sociabilidade, a nova moda da elite também foi acompanhada por uma plateia atenta, como no turfe antes dela. Com a popularização das corridas de bicicleta, o Velódromo foi inaugurado em 1895 pelos Silva Prado. Foram erguidas arquibancadas para mil pessoas, e era cos- 
tume que a maior parte ficasse de pé, como acontecia no turfe. Continuando as comparações, notamos que o turfe e o ciclismo guardavam semelhanças, mas que as diferenças são mais importantes para o entedimento do processo histórico que se desenrola: o turfe remetia à vida no campo, aos criadores de animais; o ciclismo aparecia como símbolo da tecnologia industrial, da vida no meio urbano; no turfe, o protagonista era o animal e o cavaleiro era contratado para representar o criador de cavalos que se sentava confortavelmente na tribuna; no ciclismo, o protagonista era aquele que pedalava, o veloceman, considerado então como um atleta.

Era uma novidade que membros da elite realizassem um esforço físico que, no limite, servia como divertimento das classes subalternas. Nas palavras de Gambeta:

Eles, que na infância assistiram de perto aos rigores da escravidão nas fazendas de suas famílias, que vinham da velha cultura senhorial onde o trabalho era desvalorizado e se evitara fazer tarefas mecânicas em público, agora davam demonstrações de máximo esforço físico diante de plateias. (p. 101)

O que me parece, mas não foi apontado por Wilson, é que essa nova geração das parentelas estava mais preocupada com as rivalidades entre si do que com o espetáculo para o público; uma versão individual das rivalidades dramatizadas pelos clubes nos campeonatos de futebol, que dramatizariam, depois, rivalidades entre grupos diferentes da elite (italianos, ingleses, paulistanos, alemães). Se havia as rivalidades horizontais, verticalmente ainda havia, como no turfe, a necessidade de se dinstinguir. Os rapazes costumavam doar a arrecadação das bilheterias do clube de ciclismo, algo que "até fazia parte do ar esnobe". (p. 101)

Sobre a decadência do ciclismo, Gambeta aponta algo semelhante ao que é descrito no caso do turfe. O ciclismo foi dominado, aos poucos, por corredores profissionais, com origens subalternas, especialmente imigrantes com algum capital. O esporte deixou, portanto, de servir como forma de distinção, e por isso foi abandonado pelos rapazes ricos. No turfe, quando as apostas da população trabalhadora se sobrepuseram às dos criadores de animais, houve também um progressivo abandono da prática. A essa altura é importante ressaltar: os esportes de espetáculo são apenas uma das tantas práticas que a elite paulistana importou. O contato com a vida europeia era um privilégio e, portanto, essas atividades eram essencialmente uma forma de distinção. Pensando nisso, conseguimos entender melhor porque o turfe, e depois o ciclismo, foram progressivamente abandonados após uma certa popularização. 
Temos, a essa altura, três fatores centrais: o turfe inaugurou um hábito de plateia, que continuou no ciclismo. Este último, além de construir a imagem do atleta, permitiu que os filhos da elite se distinguissem ainda que realizando esforço físico para divertimento das classes subalternas.

O historiador mantém seu fio condutor e, enquanto narra as crises do ciclismo, explica o crescimento do futebol. Para tanto, novamente são utilizados elementos externos ao esporte, numa narrativa própria da história social. O momento era de adesão apressada a novos hábitos, as novidades eram incorporadas ao cotidiano com frequência. Gambeta cita "o relógio de pulso, a máquina de escrever, o telefone, a bicicleta, o patim, o elevador (...)" (p. 170) e, mais importante, a bola e os jogos atléticos. Com a decadência do turfe, conhecemos o crescimento e o aurge do ciclismo. Quando a elite abandona este último, chegamos, enfim, ao futebol.

Wilson Gambeta não é o primeiro autor a desconstruir o mito de fundação que coloca Charles Miller como pai fundador do futebol no Brasil (um discurso cuidadosamente construído pelas elites), mas, ao operar o conceito de parentela e tratar desse processo de modernização da vida urbana, o historiador nos mostra com mais clareza o desenrolar desta história. O esporte foi incluído aos poucos no Velódromo, aproveitando o espaço central, praticado em meio a espetáculos de variedades e apresentações de maravilhas da ciência e tecnologia - o que reforça a ideia de um período voltado às novidades e inovações. Nesse afã de contraposição a uma tradição rural, o futebol foi mais uma novidade entre tantas, e logo seria a mais nova forma de dinstição social dos filhos homens das famílias ricas.

Indo na contramação de explicações anacrônicas que colocam o futebol como intrinsecamente interessante, espetáculo único e imbatível, Gambeta explica que o futebol parecia frustrante para a cultura esportiva da época, familiarizada com "disputas segmentadas, com o ritmo veloz e duração curta dos páreos", típicas do ciclismo e das corridas de cavalo, nas quais o "êxtase acontecia nas chegadas sequenciais, com resultados imediatos, sem empates", expectativas e tensões aguçadas pelas apostas. (p. 125)

$\mathrm{O}$ autor historiciza o esporte, narra o crescimento do futebol como fruto de relação sociais e processos históricos. Experiências "que circulam de um esporte para outro", do turfe ao ciclismo, do ciclismo ao futebol. Nas palavras de Gambeta:

Uma atividade cultural importada só se incorpora quando a sociedade receptora decodifica os valores nela contidos e atribui sentido social à sua simbologia, ainda que através de ressignificações (...). As plateias se empolgam quando estabelecem identidades com os contendores e desenvolvem sensibilidades para os momentos de tensão vividos na 
disputa. São experiências emotivas que circulam de um esporte para outro e ganham novos significados entre as gerações. (pp. 127-128)

No turfe não havia uma constituição de relações de solidariedade permanentes entre expectadores e participantes, uma vez que os páreos mudavam frequentemente. No ciclismo, a identificação se dava individualmente com cada corredor, não com o veloclube. O "sentimento egoísta das apostas singularizava as paixões nesses esportes" (p. 136), mas isso não me parece tão relevante quanto a descontinuidade, impeditiva a uma construção identitária. Há apostas no futebol, o mesmo acontece no rugby (na Inglaterra, França e Argentina, por exemplo), mas ainda assim as identidades são construídas. Portanto, discordo do autor quanto ao impacto das apostas nesse processo. De toda forma, porém, a explicação construída no livro não depende deste elemento.

Segundo o historiador, a "transição das competições individuais em velocidade para os embates coletivos entre equipes colaborou para desencadear a devoção aos clubes" (p. 136). Surgem e crescem os "partidos", chamados mais tarde de torcidas. Construíam-se rivalidades competitivas que teatralizavam a vida urbana em confrontos entre equipes. Sucediam-se campeonatos anuais, encontros repetidos até o cobiçado desfecho. "Os campeonatos por pontos corridos (...) equivaliam às tramas dos romances folhetins". (p. 179)

A comparação não é trivial. Trata-se de uma leitura precisa que nos mostra características do esporte e de suas formas de organização não como razões intrínsecas à sua difusão, mas sim como elementos da história social do período - neste caso, a cultura dos folhetins - que, sendo equivalentes a certos elementos do esporte, facilitaram e ampliaram a boa recepção do futebol. A partir daí, observamos dois processos distintos e relacionados: a descentralização da prática do futebol pelo futebol informal e a constituição do futebol de espetáculos por meio de clubes, ligas e federações.

No jogo informal da elite, muitas vezes participavam pobres, os filhos dos criados, e mulheres. Já no jogo do "team de verdade", não, já que “(...) nos espetáculos o breve congraçamento entre classes servia para distinguir os atores principais, os que usavam o símbolo do clube" (p. 220). Essa distinção servia para reafirmar, ao mesmo tempo, o passado e a modernidade, a tradição e o dinamismo, no que Wilson Gambeta chama de "identidade de dupla face" (p. 170). No que diz respeito ao futebol de espetáculos, duas relações sociais podem ser observadas a essa altura: a relação vertical que distanciava os protagonistas em campo dos assistentes comuns e a rivalidade horizontal, entre clubes.

Se o espetáculo - conforme Debord - é uma relação social mediada por imagens, e se há o futebol de espetáculos como imagem - conforme Gambe- 
ta - o palco principal dessa mediação era o Velódromo da Consolação, onde o grupo dominante - a elite paulistana - comunicava seu domínio, e o destinatário dessa informação - a classe trabalhadora - aparecia como assistente deste espetáculo, como torcida. Assim se dava a relação vertical. Ainda que jogasse, informalmente, o mesmo jogo, a classe trabalhadora não participava do espetáculo, pelo menos não atleticamente. Essa cultura esportiva na qual o futebol se desenvolveu tinha formas e significados diferentes para classes diferentes, uma diferenciação pincelada pelo autor, mas que acrescentaria muito à análise caso fosse aprofundada. Explico: para as parentelas, o esporte, além de uma forma de distinção, era parte do que Gambeta chama de cultura dos prazeres. Os herdeiros da elite jogavam futebol como sportsmen, entendiam-se modernos e distintos ao emular práticas observadas na Europa. Os trabalhadores - os subalternos, os ex-escravizados, os imigrantes pobres -, por outro lado, praticavam esportes naquilo que Adorno chama de tempo livre ${ }^{2}$, aquele tempo que não é dedicado ao trabalho mas que existe em função dele, algo como uma recarga de energia (física e mental) essencial para a boa performance no tempo de serviço.

Situação diferente é observada quando isolamos apenas os privilegiados. Nesse caso, a análise identifica as rivalidades horizontais a que já me referi, cujos protagonistas, no recorte temporal de Gambeta, eram: o Clube Atlético Paulistano, formado por jovens de famílias cafeicultoras ligadas entre si e aos Silva Prado por laços de parentesco, negócios e política; o SPAC, fundado pelos filhos dos ingleses que chegavam ao Brasil por empresas como a Light e a São Paulo Railway Company; a A.A. Mackenzie College, organizada pelos estadunidenses da instituição presbiteriana; o Sport Club Germania, fundado pela colônia alemã; e, em meio ao teatro das nacionalidades, havia ainda o Sport Club Internacional, que se pretendia aberto a todas origens (de nacionalidade, não de classe).

O clube aparece como entidade de livre associação, uma extensão da parentela. Por isso, entendo que as rivalidades criadas neste esporte eram também rivalidades familiares. Uma disputa dramatizada que passava de team para team dentro da mesma agremiação, do mesmo clube. O perdedor de um ano ficava ansioso pelo campeonato seguinte, quando poderia reverter o resultado, ou, caso saísse vitorioso, voltaria para defender sua supremacia no próximo ano. Essa dinâmica demoraria algum tempo para ser

2 ADORNO, Theodor. Tempo livre. In: Idem. Indústria cultural e sociedade. São Paulo: Paz e Terra, 2002. 
ressignificada, com a entrada de outros agentes e outras identidades nessa teatralização da vida urbana.

Reforçando essa ideia de teatro das rivalidades familiares, os espetáculos da Liga Paulista de Football (LPF) eram uma oportunidade para a oligarquia paulista recuperar as atenções que vinha perdendo para as associações atléticas de imigrantes. Os craques da bola, filhos da elite, eram apresentados como a nova geração de líderes. Não por acaso, como aponta o autor, nesse momento a imagem esportiva das insituições de ensino era fator determinante na escolha da escola dos filhos.

Esse teatro que dramatizava as tensões sociais dentro de São Paulo teve desdobramentos mais amplos. O texto alcança a nacionalização do futebol e as relações diplomáticas (p. 282). Incorporado aos poucos à diplomacia, o esporte sinalizava uma relação cordial e amistosa, propunha relacionamentos pacíficos e representava uma posição de igualdade. Logo, São Paulo começa a receber visitas de times estrangeiros (p. 286), que geralmente davam verdadeiras aulas de futebol aos times paulistanos.

A rivalidade com os cariocas - um par antitético, segundo o autor - causava cada vez mais atritos e instabilidade política. O futebol passava por um período de desorganização e conflitos em São Paulo - falamos aqui da virada dos anos 10 do século XX. Esse momento de crise institucional se refletia nos espetáculos, já que somente os confrontos contra estrangeiros e cariocas mobilizavam grandes plateias. São momentos de encontro do campo político com o campo esportivo, já bem consolidado a essa altura.

A elite paulistana se incomodava com a suposta violência do esporte, trazida - na visão elitista - pela entrada das classes subalternas. Não houve, nessa visão elitista, a diversão moralizadora que fora idealizada. Os membros das parentelas, portanto, bradavam pela restauração da ordem, enquanto o futebol rebelde escapava da pedagogia social dos conservadores (p. 306). O processo, como descrito no livro, parecia ser irreversível. Quanto maior a difusão do futebol por todas as camadas sociais, menor a importância dele como meio de distinção da elite, que, por essa razão, distribuía-se em outros esportes: o remo, o tênis, o automobilismo, o hipismo e a aviação esportiva.

Depois de termos passado pela constituição dos espetáculos esportivos e pelos espetáculos de futebol, chegamos ao terceiro momento: a transformação do campo esportivo, o início de mais um longo processo, que escapa ao recorte deste livro e alcança a década de 1930. O futebol com novas regras, jogadores convidados, remunerações, a ascensão de novos clubes. A pedadogia social pretendida pela elite falhou, as parentelas controlavam cada vez menos a política e, portanto, a função social dos espetáculos futebolísticos. A distin- 
ção social neste esporte já era algo do passado. Há, como forma de resistência, uma cisão institucional com a criação da "liga conservadora" (p. 345), uma reação contra o profissionalismo que acaba sendo apenas mais um insucesso.

Como símbolo dessa fase decadente, que encerra o estudo de Gambeta e abre a porta para tantos outros, temos o despejo do Clube Altético Paulistano, retirado do Velódromo para que o terreno fosse loteado. Os clubes que protagonizaram esse livro começam, então, a se reorganizar, voltando suas forças para outras atividades, outros jogos, e aos poucos saindo do cenário do futebol, que a essa altura já começa a se nacionalizar e a trilhar o difícil caminho da profissionalização (p. 395). Com maior duração e maior influência se comparado ao turfe e ao ciclismo, o futebol finalmente tem o mesmo destino (para a elite) dos esportes anteriores. Deixa de ser uma forma de distinção e, na sua forma de espetáculo, deixa de comunicar e reforçar uma dominação social.

Em A Bola Rolou, conhecemos a história do turfe, do ciclismo e do futebol, o processo de modernização da vida urbana no qual os esportes têm papel central. Entendemos melhor a mediação entre a vida privada e a vida político-partidária exercida pelos clubes esportivos de elite, assim como a ação política das ligas e federações do início do século XX. Com a história do Velódromo, passamos a entender melhor o processo pelo qual o estádio se torna uma arena de espetáculos e espaço de uma nova sociabilidade. Ainda, temos contato com uma análise do futebol de espetáculos como comunicador de valores morais, uma pedagogia social de cunho conservador comandada pelas parentelas paulistanas. A narrativa é completa no que se propôs a fazer mas, como toda grande obra, abre diversos caminhos de pesquisa. Wilson Gambeta nos revela temporalidades de três gerações, uma janela no espaço-tempo que, de forma deliciosa e rica, nos mostra as diversas faces de São Paulo na virada do século XIX para o XX, tornando mais completo o nosso conhecimento a respeito deste período que ainda merece mais estudos.

\section{Bibliografia}

ADORNO, Theodor. Tempo livre. In: Indústria cultural e sociedade. São Paulo:

Paz e Terra, 2002.

DEBORD, Guy. The Society of the Spectacle. New York: Zone Books, 1995.

GAMBETA, Wilson. A bola rolou: o velódromo paulista e os espetáculos de futebol. São Paulo: SESI-Editora, 2015.

Recebido: 27/09/2016 - Aprovado: 25/11/2016 